\title{
Fluid Management for Critically III Patients: A Review of the Current State of Fluid Therapy in the Intensive Care Unit
}

\author{
Erin Frazee $^{a}$ Kianoush Kashani ${ }^{b, c}$ \\ ${ }^{a}$ Department of Pharmacy, ${ }^{b}$ Division of Nephrology and Hypertension, Department of Medicine, and ${ }^{\mathrm{c}}$ Division of \\ Pulmonary and Critical Care Medicine, Department of Medicine, Mayo Clinic, Rochester, Minn., USA
}

\section{Key Words}

Colloid - Crystalloid - Intensive care unit · Intravenous fluid . Resuscitation

\begin{abstract}
Background: Intravenous fluids (IVF) are frequently utilized to restore intravascular volume in patients with distributive and hypovolemic shock. Although the benefits of the appropriate use of fluids in intensive care units (ICUs) and hospitals are well described, there is growing knowledge regarding the potential risks of volume overload and its impact on organ failure and mortality. To avoid volume overload and its associated complications, strategies to identify fluid responsiveness are developed and utilized more often among ICU patients. Apart from the amount of fluid utilized for resuscitation, the type of fluid used also impacts patient outcome. Colloids and crystalloids are two types of fluids that are utilized for resuscitation. The efficacy of each fluid type on the expansion of intravascular volume on one hand and the potential adverse effects of each individual fluid, on the other hand, need to be considered when choosing the type of fluid for resuscitation. The negative impact of hydroxyethyl starch on kidney function, of albumin on the mortality of head trauma patients and chloride-rich crystalloids on mortality and kidney function, are only examples of new devel-
\end{abstract}

opments in the field. Summary: In this paper, we will review the impact of fluid overload on patient outcomes, define the fluid challenge, describe the differences in static and dynamic estimates of fluid responsiveness, and review the effect of different types of fluid on patient outcome. Key Message: Avoiding fluid overload by choosing the appropriate amount of fluids in patients who are fluid-responsive on one hand, and treating IVF like other medications, on the other hand, are the major changes. Whenever clinicians decide to prescribe IVF, they need to weigh the risks and benefits of giving fluid and also the advantages and side effects of each fluid type in order to optimize patient outcomes.

(c) 2016 S. Karger AG, Basel

\section{Introduction}

Intravenous fluids (IVF) are routinely used in intensive care units (ICUs) and hospitals in order to restore effective blood volume and maintain organ perfusion

Contribution from the 1st Conference of the International Network of Diagnosis and Management of Acid-Base, Electrolyte, and Fluid Alterations 'Diagnosis and Management of Acid-Base, Electrolyte and Fluid Alterations in Critically-III Patients' held in Shanghai and Hangzhou on January 14-16, 2016.

\section{KARGER}

E-Mail karger@karger.com

www.karger.com/kdd
C 2016 S. Karger AG, Basel

2296-9381/16/0022-0064\$39.50/0
Kianoush Kashani, MD

Division of Nephrology and Hypertension

Department of Medicine, Mayo Clinic

200 First Street SW, Rochester, MN 55905 (USA)

E-Mail kashani.kianoush@mayo.edu 
during shock state resuscitation. Despite significant advances made in the resuscitation of critically ill patients, the optimal dose and type of IVF to be used during resuscitation remain undetermined. This has resulted in significant variability in global resuscitation practices and, therefore, has impacted the outcomes of such interventions.

The optimal IVF dose is not yet defined. The Surviving Sepsis Campaign [1] recommended an initial dose of $30 \mathrm{ml} / \mathrm{kg}$ body weight for patients who are in septic shock. In addition, the authors suggested the goals of such resuscitation to be a central venous pressure (CVP) of 8-12 $\mathrm{mm} \mathrm{Hg}$, a mean arterial pressure of $\geq 65 \mathrm{~mm} \mathrm{Hg}$, a urine output of $\geq 0.5 \mathrm{ml} / \mathrm{kg} / \mathrm{h}$, a central venous (superior vena cava) or mixed venous oxygen saturation of 70 or $65 \%$, respectively, or a normalization of serum lactate. In the most optimistic view, the role of these aforementioned targets of IVF resuscitation is disputed in the literature, if not negated. The static measures of fluid responsiveness have proven to be inaccurate, resulting in significant volume overload and its related adverse effects [2-5]. On the other hand, the dynamic tests of fluid responsiveness are limited to a subgroup of patients who are mechanically ventilated and have no respiratory effort.

In the first section of this review, we describe the current state of knowledge regarding available measures for evaluation of volume responsiveness in ICU patients. Apart from appropriate dosing of IVF, the type and composition of IVF have been the focus of recent studies [6]. A choice between colloids and crystalloids and the different impact of chloride-rich versus balanced solutions can affect not only the amount of fluid needed to achieve the goals of fluid therapy but can also influence the outcomes of patients under resuscitation. In the second section of this review paper, we describe the differences between fluid types and the newest developments in the field.

\section{Fluid Overload}

Although fluid overload is traditionally defined as an increase in admission weight by $10 \%$, some authors characterize it in accordance with documentation of suggestive clinical signs and symptoms, including the development of new pitting edema, crackles, or anasarca as compared with admission $[1,2,7]$. Regardless of the definition of fluid overload used, many studies report its significant association with higher mortality and morbidity among ICU patients. Boyd et al. [8] showed, among a large cohort of septic shock patients who re-

Fluid Management in the Intensive Care Unit

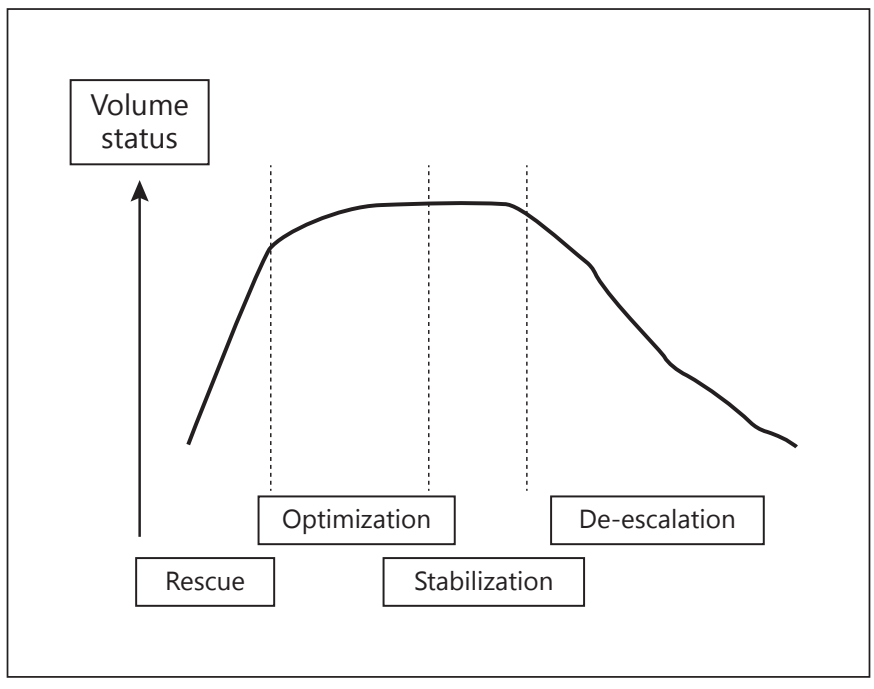

Fig. 1. The four stages of volume resuscitation therapy [12].

quired vasopressors, that greater positive fluid balance $12 \mathrm{~h}$ and 4 days after resuscitation was associated with higher mortality. They also reported a direct relationship between CVP within the first $12 \mathrm{~h}$ and mortality, wherein individuals with a CVP $>12 \mathrm{~mm} \mathrm{Hg}$ experienced the highest mortality. In another large observational cohort study, Vaara et al. [6] demonstrated a significantly higher 90-day mortality rate among patients who became volume-overloaded prior to the initiation of renal replacement therapy (RRT). Kelm et al. [7] described a large single-center cohort of patients with severe sepsis and septic shock who underwent early goal-directed therapy. They defined volume overload based on the clinical criteria and found a significantly higher hospital mortality rate and the need for fluid-related interventions, such as paracentesis and use of diuretic agents, among those with fluid overload.

As the result of such emerging data, the Acute Dialysis Quality Initiative (ADQI) XII was focused on IVF dosing and fluid overload. The ADQI XII investigators reiterated four main stages during volume resuscitation, initially proposed by Vincent and colleagues $[9,10]$ : rescue, optimization, stabilization, and de-escalation (fig. 1). During the first stage (rescue), the main focus is on the appropriate use of IVF to improve perfusion deficits. During the optimization and stabilization stages, the main focus is on maintaining appropriate perfusion while avoiding further volume overload. Finally, the last stage (de-escalation) is concentrated on removal of the fluids that were used during resuscitation. 


\section{Determination of Fluid Responsiveness}

Fluid responsiveness is an increasingly accepted concept in the management of critically ill patients with hypotension. Although there is no consensus definition of fluid responsiveness, some authors defined it as an increase in the cardiac output or stroke volume following a preload challenge [5]. Preload challenge could be accomplished by both fluid challenge and/or passive leg raising.

It is crucial to distinguish the differences between fluid challenge and fluid bolus. As per the ADQI XII, the fluid bolus is a therapeutic intervention and entails the rapid infusion of at least $500 \mathrm{ml}$ over a maximum of 15 min to correct hypotensive shock [10], while the fluid challenge is used as a diagnostic tool and is defined as a rapid infusion of $500-1,000 \mathrm{ml}$ of crystalloids or $300-$ $500 \mathrm{ml}$ of colloids over $30 \mathrm{~min}$ to provide information regarding the impact of fluids in the optimization of tissue perfusion $[1,11]$. During the fluid challenge, apart from the type of fluid (colloid vs. crystalloid) and the rate of infusion, the goals and safety limits need to be determined. The aim of the fluid challenge is generally to correct the oxygen supply-demand mismatch and hypoperfusion state and to improve the signs and symptoms of shock. The safety limits include recognition of signs and symptoms of volume overload, pulmonary edema, hypoxemia and heart failure.

Although fluid challenges are commonly used to evaluate preload responsiveness, their performance as a test is contested in the literature. In a systematic analysis of the literature, Michard et al. reported that only $52 \%$ of the 406 episodes of fluid challenges in 334 patients were able to increase cardiac output or stroke volume [12]. These data potentially indicate that in $48 \%$ of the patients the fluid challenge not only did not provide benefit but that it added the burden of its related volume overload.

\section{Static Measures of Fluid Responsiveness}

Two of the most commonly used measures of fluid responsiveness have been CVP and pulmonary artery occlusion pressure (cardiac filling pressures) as surrogates for the right and left ventricular end-diastolic volume (preload), respectively. Following the description of the Frank-Starling curve in 1914 in an isolated heart-lung canine model for investigation of cardiac output, CVPs have been investigated and used as a measure of preload [13]. Therefore, it was assumed that any increase in CVP, as an independent variable ( $\mathrm{x}$-axis in the Frank-Starling curve), could be associated with a rise in cardiac output [4].

During recent decades, the utility of the pressures in the central venous system and in the systemic and pulmonary vasculature in the prediction of fluid responsiveness have been challenged. The first important point is that using pressure measures to estimate intraventricular volumes assumes that there is a linear relationship between pressure and volume while, indeed, this relationship is curvilinear [3]. Therefore, the rate at which CVPs rise in response to additional volume, rather that the absolute measure, should be considered as an important determinant of preload. In addition, factors like poor ventricular compliance due to the long-term effects of systemic or pulmonary hypertension, restrictive ventricular diseases, constrictive pericardial physiology, and valvular malfunctions all can distort the pressure-volume relationship and thus impact the performance of central pressures in fluid responsiveness prediction. The second prominent issue is that each patient has different myocardial contractility and therefore has an individualized Frank-Starling curve shape and steepness. Patients who suffer from heart failure only have limited increase in their cardiac output in comparison with normal individuals when they have comparable cardiac filling pressure and are given a similar amount of fluid.

These physiologic considerations further translated into several studies to investigate the use of cardiac filling pressure among those who are being resuscitated. More than 30 years ago, Shippy et al. reported a poor correlation between CVP and blood volume changes during resuscitation of patients with hypovolemic shock [14]. Marik et al. [5] in a recent systematic analysis found no relationship between cardiac filling pressure (particularly CVP) and fluid responsiveness (the area under the receiver operating characteristic curve was 0.56 ) among ICU and operation room patients. They recommended to completely abandon this practice.

\section{Dynamic Measures of Fluid Responsiveness}

The poor performance of static measures of fluid responsiveness created the need for the development of other means to appreciate fluid responsiveness. Further investigations showed that among patients who are mechanically ventilated, heart-lung interactions could provide an opportunity for evaluation of fluid responsiveness. When both ventricles are fluid-responsive, during mechanical ventilation the stroke volume changes with 
each breath, and its extent depends on the degree of fluid responsiveness. In patients who do not have any internal respiratory drive and are on mechanical ventilation, intrathoracic pressure is theoretically determined by the ventilator. During positive pressure inspiration, an increase in intrathoracic pressure results in decreased preload and, therefore, stroke volume. On the contrary, during expiration, a rapid decline in intrathoracic pressure is associated with an increase in venous return, preload, and stroke volume. These dynamic changes in stroke volume in response to the respiratory cycle could be used for determination of fluid responsiveness. In patients who are fluid-responsive, variation in right and left stroke volume during the respiratory cycle is correlated with changes in pulse pressure. Thus, significant variability of pulse pressure during the respiratory cycle has been validated for prediction of fluid responsiveness $[15,16]$. Other indicators of stroke volume variabilities during mechanical ventilation, including esophageal Doppler for aortic blood flow measurement (as a surrogate for stroke volume), inferior vena cava collapsibility index and others have been tested and validated to predict fluid responsiveness [17, 18]. There are also some caveats to the use of the heartlung relationship in the prediction of fluid responsiveness. To be able to use such a relationship, patients need to have no respiratory effort while on the mechanical ventilator. In addition, the tidal volume for the course of the test should be set at $8-10 \mathrm{ml} / \mathrm{kg}$. Extremely limited lung compliance, beat-to-beat pulse pressure variability due to arrhythmias, right ventricular failure, and open chest wound restrict the value of these tests.

Each individual stores approximately $300 \mathrm{ml}$ of whole blood in the lower extremities. Using passive leg raising would allow a rapid increase in preload without adding to the total body volume. It has been suggested that changes in stroke volume following passive leg raising could predict volume responsiveness [18].

\section{Fluid Types}

Two primary types of resuscitation fluid exist for critically ill patients: colloids and crystalloids. Patient-specific factors, geographic and institutional predilections, cost and access each serve as determinants of the type of fluid selected for a given scenario. In 2010, an international point-prevalence survey in 391 ICUs found that $48 \%$ of resuscitation episodes were treated with colloids, another $33 \%$ with crystalloids, and the remaining with blood products. After adjustment for patient and prescriber

Fluid Management in the Intensive Care Unit characteristics, regional variations significantly influenced fluid choice. Within the colloid-based treatment regimens, although starches were the most commonly used overall, particularly in Canada, Western European countries, and New Zealand, there was a marked international variability, with albumin being the main agent in the United States and gelatin in Hong Kong [19]. Notably, this epidemiologic work predates many of the significant high-quality clinical trials recently published on the topic. Future evaluations may identify a shift in prescribing behavior based on these findings.

\section{Colloids}

Colloids consist of a class of high-molecular-weight compounds suspended in a carrier vehicle that, under normal physiologic conditions, remain in the intravascular space, confer oncotic pressure, and provide plasma expansion [20]. Albumin and starches are the most commonly used colloids in practice due to their duration of action and tolerability, but gelatins and dextrans also remain available [5]. In each of these cases, the oncotic gradient is thought to draw interstitial fluid into the intravascular space, therein increasing the efficiency of volume expansion relative to a comparable amount of crystalloid. Yet despite this theoretical benefit, randomized controlled trials of all-comers with critical illness requiring resuscitation have failed to demonstrate superiority of colloids over crystalloids. Furthermore, the magnitude of the volume-sparing potential of colloids is more limited than originally hypothesized, with a ratio of approximately 1 liter of colloid to at most 1.5 liters of crystalloid in high-quality clinical trials [21-23].

Human albumin, a natural colloid, is the most widely studied of these agents for the resuscitation of critically ill patients. Albumin is synthesized endogenously by the liver and is responsible for up to $80 \%$ of intravascular colloid oncotic pressure. In addition to the potential for an oncotic gradient favoring plasma expansion, laboratory and preclinical models have found that endogenous albumin exhibits antioxidant effects, scavenges free radicals, serves as a critical transport protein for many molecules and medications, and may modulate inflammatory response [24]. It is unclear whether the administration of exogenous commercially available iso-oncotic (4-5\%) or hyper-oncotic (20-25\%) albumin preparations comparably affects these non-colligative processes and whether this translates into improvements in clinical outcomes. Furthermore, as this is a product derived from pooled human plasma, it is a limited resource and is associated with considerable expense compared to other colloids and crystalloids. 
In 1998, the Cochrane Injuries Group Albumin Reviewers [25] conducted a meta-analysis of albumin use in critically ill patients, which surprisingly demonstrated heightened mortality in patients administered albumin compared to those who received no albumin or crystalloid therapy. These findings were not corroborated by a subsequent analysis [26] and have been questioned due to the heterogeneity of the interventions (iso-oncotic albumin for resuscitation versus hyper-oncotic albumin for supplementation), disparate patient populations, and the small sample sizes of the included trials. At a minimum, the meta-analysis failed to demonstrate the superiority of albumin-based resuscitation and heralded a need for large-scale research in this area. The 2004 Saline versus Albumin Fluid Evaluation (SAFE) trial filled this void as a 6,997-patient blinded clinical trial, which compared $4 \%$ albumin and $0.9 \%$ sodium chloride $(\mathrm{NaCl})$ for ICU resuscitation. No difference existed between groups for the primary endpoint of 28-day all-cause mortality, but in the 492 (7\%) patients with traumatic brain injuries, the relative risk of death was greater with albumin compared to saline at 1.62 [95\% confidence interval (CI) 1.12-2.34; $\mathrm{p}=0.009$ ] [22]. Further, analyses indicated that this detrimental effect was limited to patients with severe traumatic brain injuries, perhaps due to a coagulation defect induced by the colloid [27].

In contrast to the trauma population in whom crystalloid appears to be the fluid of choice, among individuals with severe sepsis and septic shock in SAFE, the adjusted relative risk of death at 28 days for albumin patients was 0.71 (95\% CI $0.52-0.97$ ), which indicated a protective pattern [22]. Importantly, this finding was derived from an underpowered subgroup analysis, but some have surmised that the results reflect, at least in part, the immune and inflammatory benefits of albumin in this population. However, when Caironi et al. [28] explored this effect in the ALBIOS trial through daily $20 \%$ albumin supplementation for patients with severe sepsis and septic shock, they found no improvement in mortality, length of stay or degree of organ dysfunction with albumin supplementation. No evidence of harm existed with the albuminbased resuscitation or supplementation, but given its cost and the lack of convincing, reproducible benefit seen in high-quality clinical trials and meta-analyses [29-32], the Surviving Sepsis Campaign [1] recommends restricting its use to individuals who have received a 'substantial amount of crystalloid'.

Starches are a group of semisynthetic colloids prepared by hydroxyethylation of amylopectin from sorghum, corn, or potatoes. These products may be iso-on- cotic $(6 \%)$ or hyper-oncotic (10\%) and are classified based on two main properties, their molecular weight (70-670 $\mathrm{kD}$ ), and the degree of molar substitution or, in other words, the number of hydroxyethyl groups per glucose monomer $(0.4-0.7)$ [5, 20]. First- and second-generation starches used higher molecular weights and greater molar substitution (0.5-0.7), which resulted in a lengthened duration of intravascular volume expansion [5]. Unfortunately, with this benefit came an increase in toxicity, and these early starch preparations were found to alter coagulation parameters and accumulate in the skin, liver, and kidneys, which led to pruritus and end-organ dysfunction, particularly acute kidney injury (AKI) [20]. Thirdgeneration starches, commonly referred to as 'tetrastarches', have lower molecular weights and a reduced degree of substitution (approximately $130 \mathrm{kD}$ and 0.4 , respectively), which is thought to induce less toxicity [5]. These modern hydroxyethyl starches (HES) are significantly less expensive and easier to procure than albumin, and for this reason, several recent clinical trials have explored their efficacy and safety for ICU resuscitation compared to crystalloids.

The 2012 Crystalloid versus Hydroxyethyl Starch Trial (CHEST) [23] was the largest blinded clinical trial to date comparing $6 \% \mathrm{HES}(130 / 0.4)$ to $0.9 \% \mathrm{NaCl}$ in a heterogeneous group of nearly 7,000 critically ill adults requiring fluid resuscitation. The authors found no difference in the primary outcome of 90-day all-cause mortality between the colloid and crystalloid groups, although the overall mortality of $17 \%$ was somewhat lower than anticipated. Individuals randomized to HES experienced a near doubling in the incidence of treatment-related adverse events, driven primarily by pruritus, skin rash, and a greater need for new initiation of RRT (7\% HES vs. 5.8\% saline; $p=0.04)$. In summary, HES yielded no efficacy benefit compared to saline and was associated with a heightened risk of adverse effects, particularly the need for RRT. These findings were reinforced by the multinational, randomized, non-blinded Colloids versus Crystalloids for the Resuscitation of the Critically Ill (CRISTAL) trial [21], which demonstrated no benefit on the primary outcome of 28-day mortality for colloids versus crystalloids. Although not exclusively a starch versus saline trial, $69 \%$ of the individuals in the colloid group received HES and $87 \%$ of the crystalloid-treated patients received isotonic $\mathrm{NaCl}$.

The subgroup of ICU patients with severe sepsis and septic shock is of particular interest in the HES literature due to the consistent need for early goal-directed volume resuscitation and an increased baseline risk of AKI 
Table 1. Composition of different fluids in comparison with plasma

\begin{tabular}{|c|c|c|c|c|c|}
\hline & Plasma & $\begin{array}{l}0.9 \% \\
\mathrm{NaCl}\end{array}$ & $\begin{array}{l}\text { Lactated } \\
\text { Ringer's }\end{array}$ & $\begin{array}{l}\text { Plasma- } \\
\text { Lyte } 148^{\text {a }}\end{array}$ & $\begin{array}{l}\text { Albumin } \\
5 \%\end{array}$ \\
\hline Sodium, mmol/l & 140 & 154 & 131 & 140 & $130-160$ \\
\hline Potassium, mmol/1 & 5 & - & 5.4 & 5 & $\leq 2$ \\
\hline Chloride, $\mathrm{mmol} / \mathrm{l}$ & 100 & 154 & 111 & 98 & - \\
\hline Calcium, mmol/l & 2.2 & - & 2 & - & - \\
\hline Magnesium, mmol/1 & 1 & - & 1 & 1.5 & - \\
\hline Bicarbonate, $\mathrm{mmol} / \mathrm{l}$ & 24 & - & - & - & $-b$ \\
\hline Lactate, $\mathrm{mmol} / \mathrm{l}$ & 1 & - & 29 & - & - \\
\hline Acetate, $\mathrm{mmol} / \mathrm{l}$ & - & - & - & 27 & - \\
\hline Gluconate, mmol/l & - & - & - & 23 & - \\
\hline $\mathrm{pH}$ & 7.4 & 5.4 & 6.5 & 5.5 & 7.4 \\
\hline$\left[\mathrm{Na}^{+}\right]:\left[\mathrm{Cl}^{-}\right]$ratio & $1.4: 1$ & $1: 1$ & $1.18: 1$ & $1.43: 1$ & - \\
\hline
\end{tabular}

$\mathrm{Cl}=$ Chloride; $\mathrm{Na}=$ sodium .

${ }^{a}$ Plasma-Lyte A has the same composition with the exception of a $\mathrm{pH}$ of $7.4 .{ }^{\mathrm{b}}$ Buffering salt differs according to manufacturer, but may include sodium bicarbonate or sodium chloride. from infectious, inflammatory, and hemodynamic causes. Smaller studies have found disparate outcomes with respect to the renal safety of HES in sepsis $[3,14,16,33]$. Recently, the Scandinavian Starch for Severe Sepsis/Septic Shock (6S) trial [15] sought to clarify the relationship between HES and clinical outcomes in this patient population. This high-quality large clinical trial demonstrated a significant increase in the composite primary endpoint of death or dialysis dependence at 90 days in septic adults randomized to a $6 \% 130 / 0.42$ HES compared to individuals randomized to Ringer's acetate for fluid resuscitation ( 51 vs. $43 \%$, respectively; $\mathrm{p}=0.03$ ). The composite endpoint was driven by the mortality aspect, as only $1 \%$ of the individuals who required any RRT during the follow-up period remained dialysis-dependent at study day 90 , but secondary endpoints revealed a significantly greater need for RRT overall in HES patients and fewer days alive without RRT. Notably, a long-term follow-up analysis found that the statistically significant difference in crude and adjusted mortality between groups dissipated at 6 months and 1 year of follow-up [12].

The results of the recent HES literature have been called into question because of the variability in the time to and duration of HES administration, inconsistencies in the algorithms for fluid use, presence or absence of hemodynamic instability, and inclusion of individuals with baseline renal dysfunction [34]. Regardless of these factors, no convincing evidence exists to suggest the superiority of HES over other fluid resuscitation strategies in hypovolemic critically ill patients, and the most recent iteration of the Surviving Sepsis Campaign [1] specifical-

Fluid Management in the Intensive Care Unit ly recommends against the use of HES for resuscitation in sepsis at this time.

\section{Crystalloids}

The use of salt-based fluid resuscitation in critically ill patients dates back to the cholera pandemic of the early 19th century. In the seminal work published in this field in 1832, Dr. Robert Lewins [35] described the successful resuscitation of six cholera patients with a $\mathrm{NaCl}$ - and sodium bicarbonate-based solution. In the two centuries that followed this letter, authors published many reports which characterized the relative successes associated with the use of various salt-based solutions for resuscitation [36]. These basic resuscitation solutions only limitedly resemble what we now refer to as 'normal saline', or $0.9 \%$ $\mathrm{NaCl}$. This designation as 'normal' is an obvious misnomer in that the solution of $154 \mathrm{mmol} / \mathrm{l}$ of sodium and $154 \mathrm{mmol} / \mathrm{l}$ of chloride is in no way analogous to the complex composition of the extracellular fluid. Its supraphysiologic chloride concentration (normal value 97-107 $\mathrm{mmol} / \mathrm{l}$ ), low $\mathrm{pH}$, and lack of other essential extracellular ions including potassium, bicarbonate, calcium, magnesium, and phosphorous elicit a differential physiologic effect when compared to resuscitation with more 'balanced' salt solutions, such as lactated Ringer's or Plasma-Lyte (table 1) [36, 37].

Although the clinical debate about isotonic crystalloids is in its infancy, many physiologic mechanisms explain the potentially detrimental consequences of the routine use of unbalanced, chloride-rich crystalloids in the critically ill. Excess exogenous chloride administra- 
tion has been shown to induce renal artery vasoconstriction, AKI, hyperchloremic metabolic acidosis, gastrointestinal dysfunction, and the secretion of inflammatory cytokines [37-39]. A commonly cited concern about the use of balanced salt solutions is the risk for hyperkalemia [40]; however, comparative evidence has largely invalidated this suspicion and indicated that the metabolic acidosis which ensues after large-volume $0.9 \% \mathrm{NaCl}$ administration may instead trigger extracellular potassium shifts and consequent hyperkalemia [41].

The high-quality comparative literature between isotonic crystalloids for fluid resuscitation in the critically ill is thus far limited. Four large observational studies and a single-center quality improvement initiative demonstrated associations between the use of balanced fluids and superior clinical outcomes, specifically a lower incidence of AKI and mortality when compared to isotonic saline $[4,42-45]$. In septic patients, in fact, a dose-response relationship was noted wherein an increasing proportion of balanced fluids administered during resuscitation corresponded to improved survival [43]. This favorable mortality association appears independent of severity of illness and the total volume of fluid administered $[4,11]$. Recently the $0.9 \%$ Saline vs. Plasma-Lyte 148 for ICU Fluid Therapy (SPLIT) trial was published and is arguably the highest-quality evidence available in this field to date. This cluster randomized blinded trial found no difference in the incidence of AKI, need for RRT, or mortality be- tween patients randomized to saline versus a balanced salt solution. When interpreting these findings it is critical, however, to note that the overall severity of illness was extremely low with the majority of these, being elective surgical cases with few baseline comorbid conditions. The total volume of study fluid given was approximately 2 liters, which would likely be an insufficient volume to observe any renal impact of a chloride-restrictive fluid administration strategy, especially when the overall incidence of AKI was $<10 \%$ [46].

\section{Conclusion}

Fluid management in critically ill patients has come under the spotlight in recent years. The amount and composition of fluids used in the ICU can directly impact outcomes of patients. Therefore, it is a clinical imperative to treat fluids with the same scrutiny as other medications, i.e. to know their therapeutic and toxic windows to reach the optimal dose, and when deciding the type of fluid to consider the side effect profile of each fluid and to choose them based on their risks and benefits.

\section{Conflict of Interest Statement}

All authors report no conflicts of interest.

\section{References}

1 Dellinger RP, Levy MM, Rhodes A, Annane D, Gerlach H, Opal SM, Sevransky JE, Sprung CL, Douglas IS, Jaeschke R, Osborn TM, Nunnally ME, Townsend SR, Reinhart K, Kleinpell RM, Angus DC, Deutschman CS, Machado FR, Rubenfeld GD, Webb SA, Beale RJ, Vincent JL, Moreno R; Surviving Sepsis Campaign Guidelines Committee including the Pediatric Subgroup: Surviving Sepsis Campaign: International guidelines for management of severe sepsis and septic shock: 2012. Crit Care Med 2013;41:580-637.

2 Goldstein S, Bagshaw S, Cecconi M, Okusa M, Wang H, Kellum J, Mythen M, Shaw AD: Pharmacological management of fluid overload. Br J Anaesth 2014;113:756-763.

3 Klabunde RE: Central venous pressure; in Klabunde RE (ed): Cardiovascular Physiology Concepts, 2nd edition. Baltimore, Lippincott Williams \& Wilkins, 2011, pp 107-112.

4 Berlin DA, Bakker J: Starling curves and central venous pressure. Crit Care 2015;19:55.
5 Marik PE, Cavallazzi R: Does the central venous pressure predict fluid responsiveness? An updated meta-analysis and a plea for some common sense. Crit Care Med 2013;41:17741781.

-6 Vaara S, Korhonen AM, Kaukonen KM, Nisula S, Inkinen O, Hoppu S, Laurila J, Mildh L, Reinikainen M, Lund V, Parviainen I, Pettila V; FINNAKI Study Group: Fluid overload is associated with an increased risk for 90 -day mortality in critically ill patients with renal replacement therapy: data from the prospective FINNAKI study. Crit Care 2012;16:R197.

$\checkmark 7$ Kelm DJ, Perrin JT, Cartin-Ceba R, Gajic O, Schenck L, Kennedy CC: Fluid overload in patients with severe sepsis and septic shock treated with early goal-directed therapy is associated with increased acute need for fluidrelated medical interventions and hospital death. Shock 2015;43:68-73.

8 Boyd JH, Forbes J, Nakada TA, Walley KR, Russell JA: Fluid resuscitation in septic shock: a positive fluid balance and elevated central venous pressure are associated with increased mortality. Crit Care Med 2011;39:259-265.

-9 Vincent JL, De Backer D: Circulatory shock. N Engl J Med 2013;369:1726-1734.

10 Hoste EA, Maitland K, Brudney CS, Mehta R, Vincent JL, Yates D, Kellum JA, Mythen MG, Shaw AD: Four phases of intravenous fluid therapy: a conceptual model. Br J Anaesth 2014;113:740-747.

11 Vincent JL, Weil MH: Fluid challenge revisited. Crit Care Med 2006;34:1333-1337.

12 Michard F, Teboul JL: Predicting fluid responsiveness in ICU patients: a critical analysis of the evidence. Chest 2002;121:20002008.

13 Noble MI: The Frank-Starling curve. Clin Sci Mol Med 1978;54:1-7.

14 Shippy CR, Appel PL, Shoemaker WC: Reliability of clinical monitoring to assess blood volume in critically ill patients. Crit Care Med 1984;12:107-112. 


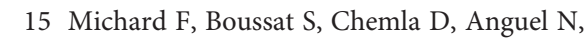
Mercat A, Lecarpentier Y, Richard C, Pinsky MR, Teboul JL: Relation between respiratory changes in arterial pulse pressure and fluid responsiveness in septic patients with acute circulatory failure. Am J Respir Crit Care Med 2000;162:134-138.

16 Michard F, Chemla D, Richard C, Wysocki M, Pinsky MR, Lecarpentier Y, Teboul JL: Clinical use of respiratory changes in arterial pulse pressure to monitor the hemodynamic effects of PEEP. Am J Respir Crit Care Med 1999; 159:935-939.

17 Feissel M, Michard F, Faller JP, Teboul JL: The respiratory variation in inferior vena cava diameter as a guide to fluid therapy. Intensive Care Med 2004;30:1834-1837.

18 Monnet X, Rienzo M, Osman D, Anguel N, Richard C, Pinsky MR, Teboul JL: Passive leg raising predicts fluid responsiveness in the critically ill. Crit Care Med 2006;34:14021407.

19 Finfer S, Liu B, Taylor C, Bellomo R, Billot L, Cook D, Du B, McArthur C, Myburgh J; SAFE TRIPS Investigators: Resuscitation fluid use in critically ill adults: an international crosssectional study in 391 intensive care units. Crit Care 2010;14:R185.

20 Myburgh JA, Mythen MG: Resuscitation fluids. N Engl J Med 2013;369:1243-1251.

-21 Annane D, Siami S, Jaber S, Martin C, Elatrous $S$, Declère AD, Preiser JC, Outin H, Troché G, Charpentier C, Trouillet JL, Kimmoun A, Forceville X, Darmon M, Lesur O, Reignier J, Abroug F, Berger P, Clec'h C, Cousson J, Thibault L, Chevret S; CRISTAL Investigators: Effects of fluid resuscitation with colloids vs crystalloids on mortality in critically ill patients presenting with hypovolemic shock: the CRISTAL randomized trial. JAMA 2013;310:1809-1817.

-22 Finfer S, Bellomo R, Boyce N, French J, Myburgh J, Norton R; SAFE Study Investigators: A comparison of albumin and saline for fluid resuscitation in the intensive care unit. $\mathrm{N}$ Engl J Med 2004;350:2247-2256.

-23 Myburgh JA, Finfer S, Bellomo R, Billot L, Cass A, Gattas D, Glass P, Lipman J, Liu B, McArthur C, McGuinness S, Rajbhandari D, Taylor CB, Webb SA; CHEST Investigators; Australian and New Zealand Intensive Care Society Clinical Trials Group: Hydroxyethyl starch or saline for fluid resuscitation in intensive care. N Engl J Med 2012;367:19011911.

24 Boldt J: Use of albumin: an update. Br J Anaesth 2010;104:276-284.

25 Cochrane Injuries Group Albumin Reviewers: Human albumin administration in critically ill patients: systematic review of randomised controlled trials. BMJ 1998;317:235240.
26 Wilkes MM, Navickis RJ: Patient survival after human albumin administration. A metaanalysis of randomized, controlled trials. Ann Intern Med 2001;135:149-164.

27 SAFE Study Investigators; Australian and New Zealand Intensive Care Society Clinical Trials Group; Australian Red Cross Blood Service; George Institute for International Health, Myburgh J, Cooper DJ, Finfer S, Bellomo R, Norton R, Bishop N, Kai Lo S, Vallance S: Saline or albumin for fluid resuscitation in patients with traumatic brain injury. $\mathrm{N}$ Engl J Med 2007;357:874-884.

28 Caironi P, Tognoni G, Masson S, Fumagalli R, Pesenti A, Romero M, Fanizza C, Caspani L, Faenza S, Grasselli G, Iapichino G, Antonelli M, Parrini V, Fiore G, Latini R, Gattinoni L; ALBIOS Study Investigators: Albumin replacement in patients with severe sepsis or septic shock. N Engl J Med 2014;370:14121421.

29 Patel A, Laffan MA, Waheed U, Brett SJ: Randomised trials of human albumin for adults with sepsis: systematic review and meta-analysis with trial sequential analysis of all-cause mortality. BMJ 2014;349:g4561.

30 Rochwerg B, Alhazzani W, Sindi A, HeelsAnsdell D, Thabane L, Fox-Robichaud A, Mbuagbaw L, Szczeklik W, Alshamsi F, Altayyar S, Ip WC, Li G, Wang M, Wludarczyk A, Zhou Q, Guyatt GH, Cook DJ, Jaeschke R, Annane D; Fluids in Sepsis and Septic Shock Group: Fluid resuscitation in sepsis: a systematic review and network meta-analysis. Ann Intern Med 2014;161:347-355.

31 Jiang L, Jiang S, Zhang M, Zheng Z, Ma Y: Albumin versus other fluids for fluid resuscitation in patients with sepsis: a meta-analysis. PLoS One 2014;9:e114666.

32 Xu JY, Chen QH, Xie JF, Pan C, Liu SQ, Huang LW, Yang CS, Liu L, Huang YZ, Guo FM, Yang Y, Qiu HB: Comparison of the effects of albumin and crystalloid on mortality in adult patients with severe sepsis and septic shock: a meta-analysis of randomized clinical trials. Crit Care 2014;18:702.

33 Osman D, Ridel C, Ray P, Monnet X, Anguel N, Richard C, Teboul JL: Cardiac filling pressures are not appropriate to predict hemodynamic response to volume challenge. Crit Care Med 2007;35:64-68.

34 Meybohm P, Van Aken H, De Gasperi A, De Hert S, Della Rocca G, Girbes AR, Gombotz H, Guidet B, Hasibeder W, Hollmann MW, Ince $C$, Jacob M, Kranke P, Kozek-Langenecker S, Loer SA, Martin C, Siegemund M, Wunder C, Zacharowski K: Re-evaluating currently available data and suggestions for planning randomised controlled studies regarding the use of hydroxyethyl starch in critically ill patients - a multidisciplinary statement. Crit Care 2013;17:R166.
35 Lewins R: Injection of saline solutions in extraordinary quantities into the veins in cases of malignant cholera. Lancet 1832;18:243244.

36 Awad S, Allison SP, Lobo DN: The history of 0.9\% saline. Clin Nutr 2008;27:179-188.

37 Yunos NM, Bellomo R, Story D, Kellum J: Bench-to-bedside review: chloride in critical illness. Crit Care 2010;14:226.

38 Wilcox CS: Regulation of renal blood flow by plasma chloride. J Clin Invest 1983;71:726735.

39 Chowdhury AH, Cox EF, Francis ST, Lobo DN: A randomized, controlled, double-blind crossover study on the effects of 2 - $\mathrm{L}$ infusions of $0.9 \%$ saline and Plasma-Lyte ${ }^{\circledR} 148$ on renal blood flow velocity and renal cortical tissue perfusion in healthy volunteers. Ann Surg 2012;256:18-24.

-40 O’Malley CM, Frumento RJ, Bennett-Guerrero E: Intravenous fluid therapy in renal transplant recipients: results of a US survey. Transplant Proc 2002;34:3142-3145.

-41 O'Malley CM, Frumento RJ, Hardy MA, Benvenisty AI, Brentjens TE, Mercer JS, BennettGuerrero E: A randomized, double-blind comparison of lactated Ringer's solution and $0.9 \% \mathrm{NaCl}$ during renal transplantation. Anesth Analg 2005;100:1518-1524, table of contents.

42 Shaw AD, Bagshaw SM, Goldstein SL, Scherer LA, Duan M, Schermer CR, Kellum JA: Major complications, mortality, and resource utilization after open abdominal surgery: 0.9\% saline compared to Plasma-Lyte. Ann Surg 2012;255:821-829.

43 Raghunathan K, Shaw A, Nathanson B, Sturmer T, Brookhart A, Stefan MS, Setoguchi S, Beadles C, Lindenauer PK: Association between the choice of IV crystalloid and in-hospital mortality among critically ill adults with sepsis. Crit Care Med 2014;42:1585-1591.

44 Shaw A, Schermer C, Lobo D, Munson S, Khangulov V, Hayashida D, Kellum J: Impact of intravenous fluid composition on outcomes in patients with systemic inflammatory response syndrome. Crit Care 2015;19:334.

45 Yunos NM, Bellomo R, Hegarty C, Story D, Ho L, Bailey M: Association between a chloride-liberal vs chloride-restrictive intravenous fluid administration strategy and kidney injury in critically ill adults. JAMA 2012;308: 1566-1572.

46 Young P, Bailey M, Beasley R, Henderson S, Mackle D, McArthur C, McGuinness S, Mehrtens J, Myburgh J, Psirides A, Reddy S, Bellomo R: Effect of a buffered crystalloid solution vs saline on acute kidney injury among patients in the intensive care unit: the SPLIT randomized clinical trial. JAMA 2015;314: $1701-1710$
Fluid Management in the Intensive Care Unit 